\title{
Ethical problems of repetitive research
}

The Working Group in Current Medical/Ethical Problems, which has presented this report, was originally set up in March 1973, and operates under the auspices of the Northern Regional Health Authority. The present members of the group are: The Rt Revd Dr $\mathcal{F} S$ Habgood, Lord Bishop of Durham (chairman); Mrs $\mathcal{F} M$ Burrow, lay member; Mr W O H Collins, retired administrator; The Rt Revd Mgr P Loftus, President, Ushaw College, Durham; Dr $\mathcal{F} M$ Parkin, consultant paediatrician; Dr $G O$ Richardson, consultant physician; Miss $D$ Turnbull, regional nurse, personnel; Professor $\mathcal{F} H$ Walker, University Department of Family and Community Medicine.

The following gave evidence to the group during the preparation of the report: Professor $R$ Hall; Professor I D A fohnston; Professor D N S Kerr; Dr F F W Miller; Professor A M Thomson; Professor $S$ Shuster.

A review of research projects submitted to the Ethical Committee of the Newcastle Area Health Authority (Teaching) since its formation in 1972 suggested that in some departments the research programmes involved the cooperation of the same patients in more than one project. It was thought proper to investigate the extent to which this is so and the ethical implications of the practice.

Advice and information were sought from a number of leading local research workers who openly discussed their research programmes and who confirmed that some patients were indeed involved repeatedly in projects. We are grateful for the ready cooperation which we received from them.

\section{Circumstances in which repetitive research occurs}

Repeated investigation of the same patient may occur simply because circumstances make it convenient for this to be done. Thus patients living within easy travelling distance of the hospital and those who already have a relationship with the investigator, either because they have been involved in previous investigations or they are under his clinical charge, are easy to approach and are likely to agree to any reasonable request. This situation may be reinforced by the encouragement of hospital dependence as cooperative patients acquire or think they acquire a better and more personal service.
On the other hand repeated investigations may be necessary for practical reasons. Academic depart? ments rightly specialize in their research interests so that expensive expertise is not needlessly duplicated? If a major subject for enquiry is a comparativel uncommon disease, particularly if this is a chroni $\mathcal{E}_{\text {O }}$ condition, such as acromegaly or chronic renal disease, it is likely that some patients will be asked to take part in more than one project. Thus the same patient may be involved, sometimes repeatedly ${ }_{2}$ in studies of epidemiology, aetiology, treatment and complications. The need for this practice may be reduced but not eliminated by cooperation between centres.

There are circumstances when repeated investiga $=$ tion is scientifically desirable. Clearly, sometimes it is appropriate for the same investigation to be repeated in the same person; for example, in patho logical conditions such as renal disease, the change? in function during the course of the disease anc with different treatments may be investigated. $P^{Q}$ similar rationale may apply in some physiologica $\vec{B}$ states, such as during and after pregnancy or in successive pregnancies. In addition, there are circumstances when it seems right for different. investigations to be carried out on the same person This applies in community studies when sometimes it would seem wasteful not to make use of a popula3 tion on whom collected data are available already. It also occurs in individuals when the relationship between previously acquired information and the present investigation offers unique opportunities.

\section{Ethical problems}

Any clinical research which is not directly for the benefit of the patients on whom it is performes poses certain ethical questions. How far is it right to expose individuals to inconvenience and risk for the possible benefit of others? In so far as medicab practice entails a relationship of trust betweerao patients and their doctors, how far is it permissible $e^{+}$ to compromise or complicate this relationship by allowing it to be used for purposes other than? healing ? Is it right to draw distinctions betweero research which has a direct bearing on a patient'

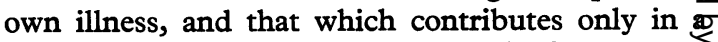
general way to the advance of knowledge?

No doubt in a great many cases the ethica dilemma is minimal, and the research hardl 
impinges on the lives of those who are undergoing it. No doubt there are also research workers who believe that the professional standards of researchers provide sufficient protection for patients. There are, however, some general considerations which would seem to apply to all experimental work on human subjects, and a brief mention of these may help to set the scene for ethical comment on the more particular problems of repetitive research.

The value of research itself, and the skill with which it is planned, are major factors to set in the balance against any possible disadvantages. There can be little excuse for trivial research of any description, especially when it inconveniences others, nor for research which is beyond the capability of the group performing it. Likewise badly planned research, however potentially valuable, loses its ethical justification if its results are not scientifically valid. But well planned and properly conducted research has a strong ethical claim on the cooperation of those who are benefiting from medical advances, often won at some cost to previous generations of patients. For this reason, it can be claimed that all have some degree of obligation to assist in the development of medicine. The more closely the research is related to a patient's own condition, and the greater the likelihood of direct therapeutic benefits, the greater the obligation to cooperate.

As against this, the possible disadvantages to patients in being the subjects of research are many and varied, not all of them obvious. The direct risk of harm, pain or discomfort may or may not be easily assessable, but it is hardly likely to be ignored. Less direct disadvantages, such as the interruption of normal treatment through being a member of a control group, can at times raise acute ethical problems, especially when an element of planned deception further complicates the relationship between patient and doctor. Psychological stress, or less tangible costs, such as the loss of dignity or privacy, may also be factors in some types of research. On the wider scale there may be general harm to professional relationships through loss of trust.

On the other hand, for some patients there may be positive advantages in being involved in research. Some may see this as a way of expressing gratitude to the medical profession, or of making constructive use of their illness. Others may enjoy an enhanced status, or the sense of receiving special attention. Others may benefit, even despite themselves, by having their altruistic impulses used in the service of their fellow sufferers.

The personal costs of being a research subject are thus difficult to specify precisely, and in the end only the patient himself can say whether he wishes to pay them, bearing in mind the general obligation to cooperate in research mentioned earlier. Informed consent is therefore rightly regarded as an essential precondition of all clinical research. Unfortunately it can prove almost as difficult to handle in practice as the notion of 'cost'.

The key question is who obtains consent from a patient, and how is this affected by the relationship between them. In a professional relationship, where patients are both dependent and anxious to please, the pressure to accept expert advice may be very strong. Medical mystique tends to discourage the frank discussion of risks and advantages, and there may well be an assumption on the professional side that the issues are in any case too complex or too technical for adequate explanation. There is the further problem that in some experiments, eg, double-blind tests, ignorance is a vital component. And there are categories of patients, of which children are the most obvious example, to whom the ideal of informed consent can hardly be applied at all.

A more conscious partnership between doctors and patients, in which open discussion and the exchange of information were regarded as the norm, would ease the problem of consent, as would a more general recognition of the experimental nature of all medical practice. But in the present state of medicine, probably the most that can be expected is adherence to some simple rules concerning consent, designed to protect patients from the emotional pressures inherent in their situation. Exceptions, as in blind experiments, can then be recognized for what they are, and made the subject of special safeguards.

These are some of the main issues which have to be considered in relation to any clinical research. Certain aspects of them are sharpened when the research is repetitive.

\section{INCENTIVES AND CONSENT}

Patients who, on account of the nature of their illness, have had prolonged and frequent contact with their clinicians are likely to be under even greater pressure than usual to agree to suggested research procedures. It is important, therefore, that research teams should be aware of the extent of their influence on such patients, and should be careful not to exploit it unfairly. The dangers of undue pressure would be minimized if consent were given in the presence of, or subsequently confirmed by, a third party, such as a trained nurse, who understood the nature of the work. Confirmation of consent by such a third party could be specified as a formal condition for approval by the Ethical Committee, if the nature of the investigation was thought to warrant it.

Another way of protecting the interests of patients would be by ensuring that the functions of research and clinical care were kept separate. Patients who are in a direct clinical relationship with a doctor are usually so willing to be helpful that their only protection, apart from the general surveillance of the Ethical Committee, lies at present in the ethical 
standards of the individual research worker who may himself be under pressure to complete his project. The suspicion that refusal to take part in, or withdrawal from, a particular study might impair their relationship with a clinician on whom they must continue to depend, is likely to act as a powerful incentive to comply with his requests. Particular care must, therefore, be taken to ensure that this suspicion is, and is seen to be, unfounded. In a situation where clinical care and research were in different hands, there would be no need even to entertain it.

There might, however, be dangers and disadvantages of a different kind in separating the two functions, and it could be argued that research workers without clinical responsibilities might be less sensitive to the condition of patients than research-minded clinicians. There are also objections in principle to the separation of research from clinical care, in that it is important to avoid exacerbating potential conflict between the two roles. Within a particular clinical/research team there may be differences of emphasis and interest among members, which could be used to counterbalance the effects of too close a relationship with patients among some members of the team, and in certain cases an internal arrangement of this kind might be an alternative to the appointment of a third party.

Long-term patients who have become familiar with research procedures may discover incidental advantages in becoming willing subjects. They may believe that they obtain better and more personal treatment by such cooperation, and this belief may easily be encouraged by a team who wish to retain a 'captive' population of 'cooperative' patients. A modest degree of such connivance is probably harmless, but its possible dangers ought to be recognized. More direct incentives, especially those of a material kind, are rarely offered, and are generally considered to be unethical.

\section{POSSIBLE HARM TO PATIENTS}

Repeated investigations increase the chances that patients may be harmed either medically or socially.

Slight risks and trivial discomforts, considered acceptable in a single investigation, may become more serious if repeated. Thus serial blood tests to patients who regenerate blood poorly may lead to significant anaemia. Repeated exposure to radiological examination or radioactive isotopes may have an unnoticed cumulative effect, especially if several unrelated investigations are made on the same patient. Biopsies may cause discomfort and alarm and, in the case of bone biopsies sometimes considerable pain; it is questionable whether discomfort of this intensity should be regularly expected of willing patients.

Social and financial disadvantages can easily multiply. Repeated admissions to hospital can cause unnecessary inconvenience and interruption to a person's pattern of life, and even outpatient investigations can be very time consuming, especiall when there is some distance to travel. There is also the danger of patients becoming even more hospital-: dependent at a time when their condition itse encourages such dependence.

We have no evidence to suggest that patients use in investigations by those who described thei research to us had suffered any harm or run an of undue risks. The researchers generally pointed out however, that the fact of being asked to look at the problem of repeated investigations had in itse $\vec{f}$ provided a valuable stimulus in alerting them to possible dangers. We were impressed by the higf standard of responsibility displayed, but our moș disturbing discovery was that, whether or not an 9 risks were being run, the state of clinical records would make it almost impossible to find out. Repeated investigations, in other words, raise theif most acute problems in the field of administration?

\section{ADMINISTRATION}

The clinical records of patients under prolonges observation and treatment become extremely voluminous. Under the present system a patient may be selected for a project on the basis of his diagnosis, without the research worker knowing what precise investigations have been done before, or even are being undertaken at the same time. There is no simple means of identifying the fact in clinical records, and doubts have been expressed to us about the effectiveness of special marks or labels on we worn files. The patient's own comments may not be a safeguard, as he may not mention previous experience, partly because he may assume that it is. already known, and partly out of a desire to help the medical profession.

Various suggestions are being canvassed fo improving the quality and usefulness of clinicat records. 'Problem-orientated records' would make information about research easier to recover? Computerization would enormously increase the amount of information retrieval, but generates its own problems concerning confidentiality. Even wider acknowledgement that the keeping of goodu records as an important part of good medical care would improve matters. Here we can simply state the problem, and urge that those concerned with thes keeping of records should devise some means of ensuring that patients who have been, or are beinge involved in research are immediately identifiable $\mathbb{D}$ In practice this might entail no more than the use of a summary card of a distinctive colour, which briefly records clinical investigations and treatmen? in one column and assistance in research activities in another, and is kept permanently at the top cover of the current volume of the hospital notes of patients who have been or are likely to be associated with research projects.

The confidentiality of records is another im 
portant area of concern. Some research projects, for example those involving psychological and social measurements, lead to highly confidential information being acquired. Repeated investigation, and hence contact with more research workers, increases the risk of improper disclosure of information. When clinical and research records are in danger of becoming confused, the risks are still further increased. On the other hand, as has been argued above, there are also risks in not identifying research in a patient's clinical records. Two guidelines, therefore, seem to be relevant: first that confidentiality should be regarded as a condition of research, and that detailed research data should be kept separate; and secondly that a reasoned summary of the research, including an easily identifiable note of the fact that research is taking place, should be recorded in the clinical file.

Some of the administrative difficulties would be eased if it could always be clearly known who was medically responsible for a particular patient. In the case of a single research project, proper liaison between the patient's doctor and the research worker should not be hard to achieve. The problems are greater when repeated research is done, and a number of different workers are involved, but this makes it all the more important for a single doctor to remain in overall clinical charge of the patient. In the light of our earlier discussion about the relationship between research and clinical care, such a doctor might have a useful role as a buffer against undue pressure from researchers. He could also safeguard patients against the dangers of the interaction of drugs in different studies. In the absence of a more adequate system of records, this personal supervision would seem to be essential, as well as being highly desirable on general medical grounds.

\section{Conclusions}

I All clinical research poses ethical problems, and these may be intensified in some aspects when the same patients are used repeatedly.

2 Ethical committees should be made aware of these problems, and should enquire whether those who have been chosen for a particular project have been involved in previous research. If so, they should be satisfied: $a$ ) that this is necessary, either for scientific or for good practical reasons; $b$ ) that there are no medical contraindications against repetitive use of the techniques proposed; $c$ ) that there is an adequate method of drawing attention to the fact that research is taking place, with details of all invasive or potentially dangerous techniques being used; $d$ ) that informed consent will be obtained and, in special cases as required by the Ethical Committee, verified by a third party; $e$ ) that deliberate inducements will not be offered.

3 We wish to draw attention to the urgent need to improve the system of medical records. 